\title{
Análise da distribuição da riqueza gerada por meio da Demonstração do Valor Adicionado
}

\author{
José Antonio Marcelino ${ }^{1}$ \\ Danielle dos Santos ${ }^{2}$ \\ Gustavo V. C. Gouveia ${ }^{3}$
}

\begin{abstract}
Resumo: Este estudo analisa, por meio da Demonstração do Valor Adicionado (DVA), a formação da riqueza gerada de duas empresas do setor de água e saneamento listadas na B3 (Brasil, Bolsa, Balcão), a Sabesp, de economia mista, e a Iguá, de economia privada, no período de 2013 a 2018. A pesquisa caracteriza-se como qualitativa e quantitativa e o método utilizado foi o estudo de caso, com análise documental, de natureza descritiva. Conforme os resultados, tanto a Sabesp quanto a Iguá possuem quase os mesmos valores com relação à distribuição de riqueza entre empregados e governo. Nos índices de participação de terceiros, a empresa Iguá possui números maiores, ao passo que, na participação dos acionistas, a Sabesp é que sobressai. Com relação aos agentes privados, a Sabesp distribui mais para terceiros, enquanto a Iguá faz uma maior distribuição para os acionistas.
\end{abstract}

Palavras-chave: Demonstração do Valor Adicionado. Distribuição da riqueza. Água. Saneamento.

\section{Analysis of the distribution of wealth generated through the Statement of Added Value}

Abstract: Using one of the components of the Social Balance Sheet, we selected the Statement of Added Value (DVA), which aims to demonstrate the formation of wealth. This research analyzes the contributions to all economic agents, and its objective is to analyze and demonstrate the formation of the wealth generated from the two companies listed in B3 (Brazil, Stock Exchange, Balcão), Sabesp, which has mixed economy, that is, it brings together private and public capital, and Iguá, which has a private economy. Both are from the water and sanitation sector, and the research was conducted from 2013 to 2018. It is necessary to consider the great importance of them for society, because they are of public utility, and also to present the wealth that was distributed to society compared to that distributed by privateagents. The theoretical framework was structured in Social Responsibility, Social Balance Sheet, Value Added Demonstration and a brief summary of the companies analyzed. The research methodology was documentary analysis, case study, descriptive, qualitative and quantitative analysis.

Keywords: Statement of Added Value. Wealth distribution. Water. Sanitation.

\footnotetext{
${ }^{1}$ Universidade Estadual do Norte do Paraná (UENP). Doutorando em Educação. Professor do Centro de Ciências Sociais Aplicadas. E-mail: josemarcelino@uenp.edu.br.

2 Universidade Estadual do Norte do Paraná (UENP). Bacharel em Ciências Contábeis. E-mail: danisantos29@hotmail.com.

3 Universidade Estadual do Norte do Paraná (UENP). Bacharel em Ciências Contábeis. E-mail: gustavovcgouveia@gmail.com.
} 


\section{Introdução}

Nos últimos anos, intensificou-se a cobrança da sociedade pela responsabilidade social das empresas. Perante esse novo contexto, cresceu também o interesse pelos métodos da contabilidade, o que torna o Balanço Social um dos instrumentos essenciais à gestão.

O Balanço Social que, antes, se restringia a questões relacionadas aos recursos humanos, expandiu-se e passou a divulgar outras informações, como (por exemplo) a Demonstração do Valor Adicionado (DVA), cuja finalidade é mostrar a formação da riqueza gerada, bem como as contribuições (ações socioambientais e econômicas) da empresa para a sociedade. Por meio da DVA, os usuários, aqueles que colaboram para a geração da riqueza, conseguem acompanhar o processo e verificar tanto como ocorreu essa participação quanto a distribuição do valor atingido. De posse dessas informações, a sociedade pode avaliar as vantagens e desvantagens em acolher tais entidades, já que tem consciência de que pode ajudá-las a alcançar seus objetivos.

Diante do exposto, tentaremos responder à seguinte questão de pesquisa: como é feita a distribuição da riqueza gerada por duas empresas de água e saneamento, uma, de capital misto, outra, de capital privado? O objetivo deste trabalho é analisar, por meio da DVA, o valor da riqueza gerada pelas empresas Sabesp e Iguá, em um período de seis anos (2013 a 2018), e mostrar a sua distribuição entre os agentes econômicos que ajudaram a criá-las.

\section{Referencial teórico}

Nesta seção, trata-se da fundamentação teórica que dará suporte para responder ao problema de pesquisa. Serão apresentados os conceitos de responsabilidade social, balanço social, Demonstração do Valor Adicionado, bem como informações sobre as empresas analisadas.

\subsection{Responsabilidade social}

Kroetz (2000, p. 24) define a contabilidade como uma ciência social que estuda a riqueza patrimonial individualizada, com o objetivo de explicar os fenômenos relativos ao patrimônio e gerar informações, tendo em vista fatores como controle, avaliação, planejamento e tomada de decisão voltada aos mais diversos usuários. Para Pinto e Ribeiro (2005), a discussão a respeito da responsabilidade social está muito atual. Desse modo, uma vez que o objetivo primordial das empresas é produzir riqueza, além de agentes econômicos, elas são também agentes sociais. Por essa razão, devem prestar conta a todos os componentes da sociedade.

$\mathrm{Na}$ visão de Pinto e Ribeiro (2005), a questão em pauta é que as empresas não devem visar somente lucros, pois têm compromissos firmados com a sociedade, como, por exemplo, defesa e preservação do meio ambiente (por meio do uso adequado de recursos naturais), empregabilidade, qualificação dos funcionários e qualidade dos produtos e serviços oferecidos.

Alicerçado nessas afirmações, este estudo destaca a importância do Balanço Social, uma ferramenta contábil que mostra de que maneira a organização distribui sua riqueza e se integra ao seu 
meio. O Balanço Social divide-se em: balanço ambiental, balanço de recursos humanos, Demonstração do Valor Adicionado e benefícios e contribuições à sociedade em geral.

\subsection{Balanço Social}

Perottoni (2011) declara que, no Brasil, o Balanço Social começou no ano de 1961, em São Paulo, com a Associação dos Dirigentes Cristãos de Empresas (ADCE), que defendia a responsabilidade das empresas com as questões sociais. Na visão desse autor, embora nos últimos anos tenha aumentado o número de usuários da informação contábil, não existe um padrão para elaborar e publicar o Balanço Social, condição que possibilita às instituições divulgarem os dados que lhes são convenientes. No entanto, vale ressaltar, essa falta de regulamentação não dificulta (ou impede) o reconhecimento das qualidades de determinada empresa.

Segundo Kroetz (2000, p. 78), o Balanço Social permite verificar os impactos das ações da entidade na sociedade de maneira geral, bem como avaliar a qualidade das relações organizacionais com seus empregados, a comunidade e o meio ambiente.

Podemos concluir, pois, que o Balanço Social é uma ferramenta para todos os usuários das informações contábeis, porque fornece dados sobre como a empresa faz a distribuição da sua riqueza gerada. Neste trabalho, volta-se a atenção para uma parte do Balanço Social, a Demonstração do Valor Adicionado, assunto a ser discutido na próxima subseção.

\subsection{Demonstração do Valor Adicionado}

Dalmácio (2004) afirma que a DVA se originou na Europa e é utilizada com frequência em países como Inglaterra, Portugal, França, Alemanha e outros. Por apresentar informações econômicas e sociais, esse demonstrativo contábil é muito requisitado, inclusive em escala internacional, principalmente devido às recomendações da Organização das Nações Unidas (ONU). A alta demanda da DVA justifica-se porque, por meio da forma pela qual essa ferramenta se desenvolve, é possível ter uma visão mais ampla de como a empresa distribui sua riqueza, assim como a participação de cada usuário nessa riqueza criada.

Segundo as palavras de Souza (2003), a Demonstração do Valor Adicionado é a combinação da informação social com a informação de natureza financeira e tem a finalidade de mostrar a riqueza gerada por uma empresa e de que maneira ela foi distribuída em determinado período.

Como se pode observar, a DVA é uma ferramenta que pode ser utilizada por diversos usuários. Suas características são apresentadas a seguir.

\subsubsection{Características das informações da DVA}

Na visão de Kroetz (2000, p. 40), a DVA é utilizada para identificar, analisar e comunicar o montante de recursos adicionados (e gerados) à economia (local, regional, nacional etc.), bem como para relacionar as fontes e aplicações dessa riqueza. 
Para Gelbcke et al. (2018, p. 1922), a DVA repassa informações a todos os agentes econômicos interessados na empresa, como empregados, clientes, fornecedores, acionistas e governo. Dalmácio (2004, p. 91) ainda afirma que "a DVA pode ser utilizada como fonte de informação pelos empregados, financiadores de recursos, administradores, governo, sócios ou acionistas, sociedade, sindicalistas, fornecedores e clientes".

São diversas as vantagens da DVA, segundo Gelbcke et al. (2018, p. 1924): demonstrar a capacidade de geração de valor e a forma de distribuição da riqueza da empresa; permitir a análise do desempenho econômico; auxiliar em cálculos do PIB e indicadores sociais; mostrar informações de benefícios obtidos pelos fatores de produção e pelo governo; informar à empresa sobre a contribuição desta para a formação da riqueza da região em que está instalada.

Dalmácio (2004) declara que a DVA contém informações importantes tanto para a sociedade quanto para a entidade, pois a tradicional Demonstração do Resultado do Exercício evidencia apenas a parcela da riqueza criada que permanece na empresa, e as outras demonstrações não indicam quanto a entidade está adicionando nem o valor distribuído.

\subsubsection{Divulgação e elaboração da DVA}

Gelbcke et al. (2018, p. 1921) esclarecem que, antes da Lei $\mathrm{n}^{\circ} 11.638 / 07$, a DVA não era necessária no Brasil. Após a promulgação do referido dispositivo legal, esse informe contábil se tornou obrigatório para as companhias abertas. Assim, tanto a elaboração quanto a divulgação da DVA devem ser feitas conforme o pronunciamento técnico do Comitê de Pronunciamento Contábeis (CPC) e fundamentadas no princípio da competência, com apresentação comparativa, tomando por base as demonstrações consolidadas.

\subsubsection{Análise da Demonstração do Valor Adicionado}

A DVA, segundo Gelbcke et al. (2018, p. 1947), pode ser analisada tanto isoladamente quanto em conjunto com outras demonstrações contábeis. Pode, ainda, ser comparada com as DVAs de outras empresas do mesmo setor ou região. Esse autor afirma que, para se verificar a DVA isoladamente, é preciso utilizar as análises vertical e horizontal, e todos esses índices podem ser usados na comparação com empresas de setores similares.

As informações contidas na DVA são úteis para que se consiga entender a relação da empresa com a sociedade, conforme sua participação na formação de riqueza e no modo como a distribui entre empregados, financiadores, governo e detentores do capital. Isso se compreende por meio da análise de quocientes ou indicadores de geração de riqueza e de sua distribuição (GELBCKE et al., 2018, p. 1949).

\subsection{Sabesp e Iguá}

A Sabesp é uma sociedade de economia mista, responsável pelo fornecimento de água, coleta e tratamento de esgotos de 375 municípios do Estado de São Paulo e mantém parceria com empresas 
privadas. É considerada uma das maiores empresas do mundo em termos de população atendida e responsável por cerca de 30\% de investimento em saneamento básico feito no Brasil.

A empresa Iguá possui uma sociedade privada, quatorze concessões e quatro Parcerias PúblicoPrivadas (PPPs). Atende a 37 municípios, que corresponde a um total de seis milhões de pessoas de comunidades de diferentes portes.

Sabesp e Iguá possuem capital aberto com ações negociadas nas bolsas de valores oficial do Brasil, a B3 (Brasil, Bolsa, Balcão). No setor de atuação, classificam-se como empresas de utilidade pública de água e saneamento.

\section{Metodologia}

Nesta pesquisa, observou-se o desempenho de duas empresas listadas na B3 no setor de água e saneamento, no período de 2013 a 2018. Para verificar as informações contidas nas DVAs, fez-se um comparativo entre o montante da riqueza gerada pela sociedade e o valor retido pelos agentes privados. Foram escolhidas duas empresas, uma de capital misto e outra de capital privado. No grupo analisado, ambas possuíam a maior distribuição de riqueza. A princípio, foram separadas quatro empresas de capital misto e duas de capital privado, sendo eleita uma de cada grupo com o maior valor adicional total a ser distribuído. Tal seleção se justificou, em primeiro lugar, pela importância de cada uma delas nos contextos econômico e social; em segundo, pela necessidade de examinar se entre empresas públicas e privadas existem diferenças na distribuição da riqueza criada e quais agentes mais se beneficiam nesse processo.

Esta pesquisa é, inicialmente, de natureza documental, um modelo que, segundo Gil (2010, p. 30) utiliza-se de dados já existentes e faz uso de documentos para finalidades diversas. Pode também ser classificada de estudo de caso, de caráter descritivo, ou seja, procurou identificar, analisar e registrar os fatos. Segundo Gerhardt e Silveira (2009), trata-se de um estudo que pretende descrever os fatos e fenômenos de determinada realidade. Realizou-se, ademais, uma análise mista (qualitativa e quantitativa) dos dados encontrados. Sobre isso, Creswell (2010, p. 27) afirma "é uma abordagem de investigação que combina as formas qualitativas e quantitativas".

\section{Análise dos dados}

Com a finalidade de examinar minuciosamente os dados obtidos, foram utilizados índices que permitem uma interligação das várias contas das demonstrações contábeis e, consequentemente, uma análise de diferentes ângulos. Para Dalmácio (2004), os critérios empregados na escolha dos indicadores para exame da DVA servem para se ter uma visão mais ampla da demonstração.

Os índices mostrados a seguir indicam as porcentagens de valor adicionado distribuídas entre os agentes econômicos que ajudaram na geração da riqueza. A Tabela 1 aponta como foi feita a distribuição da riqueza das duas empresas: 
Tabela 1 - Índices de participação

\begin{tabular}{|cccccc|}
\hline \multirow{2}{*}{$\boldsymbol{A N O}$} & $\boldsymbol{E M P R E S A}$ & $\boldsymbol{P E V A}$ & $\boldsymbol{P T V A}$ & $\boldsymbol{P G V A}$ & $\boldsymbol{P A V A}$ \\
\hline \multirow{2}{*}{$\mathbf{2 0 1 3}$} & SABESP & 26,36 & 28,9 & 27,56 & 17,18 \\
\cline { 2 - 5 } & IGUA & 25,54 & 39,43 & 26,1 & 8,93 \\
\hline \multirow{2}{*}{$\mathbf{2 0 1 4}$} & SABESP & 24,65 & 33,94 & 25,65 & 15,76 \\
\cline { 2 - 5 } & IGUÁ & 21,44 & 48,19 & 23,89 & 6,48 \\
\hline \multirow{2}{*}{$\mathbf{2 0 1 5}$} & SABESP & 16,03 & 47,88 & 28,54 & 7,55 \\
\cline { 2 - 6 } & IGUÁ & 27,39 & 70,73 & 30,84 & $-28,96$ \\
\hline \multirow{2}{*}{$\mathbf{2 0 1 6}$} & SABESP & 24,85 & 36,91 & 31,5 & 6,74 \\
\cline { 2 - 6 } & IGUÁ & 20,17 & 85,98 & 33,04 & $-39,19$ \\
\hline \multirow{2}{*}{$\mathbf{2 0 1 7}$} & SABESP & 26,59 & 28,77 & 27,4 & 17,24 \\
\cline { 2 - 6 } & IGUÁ & 24,13 & 39,08 & 28,69 & 8,1 \\
\hline \multirow{2}{*}{$\mathbf{2 0 1 8}$} & SABESP & 23,78 & 27,71 & 26,07 & 22,44 \\
\cline { 2 - 6 } & IGUÁ & 24,05 & 42,28 & 28,35 & 5,32 \\
\hline
\end{tabular}

Fonte: Elaborada pelos autores (2019).

Com fundamento na Tabela 1, é possível afirmar, no que se refere aos índices de participação:

\title{
a) Participação de Empregados do Valor Adicionado (PEVA)
}

\author{
$\mathrm{PEVA}=(\mathrm{VADE} / \mathrm{VAT}) \times 100$ \\ VADE $=$ Valor Adicionado Distribuído aos Empregados \\ VAT $=$ Valor Adicionado Total a distribuir
}

Esse índice indica o percentual da riqueza das empresas distribuído aos empregados na forma de remuneração, salários, gratificações, entre outros benefícios. De acordo com Gelbcke (2018, p. 1931), considera-se remuneração direta aos empregados (salários, $13^{\circ}$ salário, férias, horas-extras, participação de empregados nos lucros, honorários, entre outros), e benefícios (assistência médica, alimentação, transportes, FGTS, entre outros).

A Tabela 1 mostra que, apenas no ano de 2015, as empresas em questão tiveram uma grande variação: Iguá, 27,39; Sabesp, 16,03.

\section{b) Participação de Terceiros no Valor Adicionado (PTVA)}

$$
\begin{aligned}
& \text { PTVA }=(\text { VADT } / \text { VAT }) \times 100 \\
& \text { VADT }=\text { Valor Adicionado Distribuído a Terceiros } \\
& \text { VAT }=\text { Valor Adicionado Total a distribuir }
\end{aligned}
$$

Esse índice mostra o percentual de participação de terceiros no valor adicionado. Um exemplo de terceiros são os fornecedores. Segundo Gelbcke (2018, p. 1932), no grupo do PTVA entram os valores pagos ou creditados aos financiadores externos de capital, como juros, despesas financeiras, variações cambiais passivas, empréstimos e financiamentos, aluguéis, despesas com arrendamento, royalties, franquias, direitos autorais, entre outros. Observa-se, portanto, que a Sabesp tem uma distribuição muito maior, em comparação com a Iguá. 


\section{c) Participação de Governos no Valor Adicionado (PGVA)}

PGVA $=(\mathrm{VADG} / \mathrm{VAT}) \times 100$

$\mathrm{VADG}=$ Valor Adicionado Distribuído aos Governos

$\mathrm{VAT}=$ Valor Adicionado Total a distribuir

O PGVA indica o total da riqueza produzida pela entidade e distribuída aos governos. Nesse grupo incluem-se, segundo Gelbcke (2018, p. 1931), o Imposto de Renda (IR), a Contribuição Social sobre o Lucro (CSSL), a contribuição ao Instituto Nacional do Seguro Social (INSS), outros impostos e contribuições aos quais a empresa esteja sujeita, como tributos federais, estaduais e municipais. Vale ressaltar que, nos impostos compensáveis, devem ser considerados apenas os valores devidos ou já recolhidos.

Conforme se observa na Tabela 1, comparadas nesse índice, as duas empresas não apresentam grandes variações.

\section{d) Participação de Acionistas no Valor Adicionado (PAVA)}

$\mathrm{PAVA}=(\mathrm{VADA} / \mathrm{VAT}) \times 100$

VADA $=$ Valor Adicionado Distribuído aos Acionistas

VAT $=$ Valor Adicionado Total a distribuir

Esse grupo inclui, conforme Gelbcke (2018, p. 1932), a remuneração atribuída aos acionistas e aos sócios. Como se pode observar na Tabela 1, a Sabesp quando comparada com a Iguá, possui uma melhor distribuição aos acionistas nos anos considerados.

$\mathrm{Na}$ Tabela 2, é possível estabelecer uma análise com base nos índices de graus.

Tabela 2 - Índices de graus

\begin{tabular}{|c|c|c|c|c|c|c|c|}
\hline$A N O$ & EMPRESA & $G R V A$ & $G C P R$ & $G R R T$ & GCFROE & $G C A G R$ & GCPLGR \\
\hline \multirow{2}{*}{2013} & SABESP & 22,03 & 94,14 & 5,86 & $-47,54$ & 23,54 & 23,54 \\
\hline & IGUÁ & 9,16 & 89,37 & 10,63 & $-65,73$ & 16,09 & 81,31 \\
\hline \multirow{2}{*}{2014} & SABESP & 12,01 & 92,68 & 7,32 & $-55,02$ & 18,88 & 18,88 \\
\hline & IGUÁ & 7,01 & 89,34 & 10,66 & $-60,99$ & 15,98 & 93,28 \\
\hline \multirow{2}{*}{2015} & SABESP & 5,75 & 84,49 & 15,51 & $-51,93$ & 21,09 & 51,82 \\
\hline & IGUÁ & $-27,01$ & 86,93 & 13,07 & $-58,27$ & 14,41 & 107,87 \\
\hline \multirow{2}{*}{2016} & SABESP & 28,15 & 94,02 & 5,98 & $-49,42$ & 21,73 & 51,78 \\
\hline & IGUÁ & $-34,83$ & 89,32 & 10,68 & $-62,79$ & 13,14 & 163,07 \\
\hline \multirow{2}{*}{2017} & SABESP & 21,93 & 96,02 & 3,98 & $-8,5$ & 22,15 & 50,01 \\
\hline & IGUÁ & 7,52 & 88,7 & 11,3 & $-47,54$ & 20,65 & 82,52 \\
\hline \multirow{2}{*}{2018} & SABESP & 21,13 & 95,22 & 4,78 & $-42,67$ & 23,49 & 52,33 \\
\hline & IGUÁ & 4,89 & 93,39 & 6,61 & $-60,93$ & 15,24 & 51,64 \\
\hline
\end{tabular}

Fonte: Elaborada pelos autores (2019).

Conforme indica a Tabela 2 - Índices de graus - é possível afirmar, no que se refere ao: 


\section{e) Grau de Retenção do Valor Adicionado (GRVA)}

Dalmácio (2004, p. 94) assegura que "este índice indica qual o percentual de retenção do valor adicionado sob a forma de lucros retidos. Poderá, também, indicar qual o percentual de riqueza gerada será agregado ao capital próprio".

$$
\begin{aligned}
& \text { GRVA }=(\text { LR/VAT }) \times 100 \\
& \text { LR = Lucros Retidos } \\
& \text { VAT = Valor Adicionado Total a distribuir }
\end{aligned}
$$

A empresa Sabesp, no ano de 2013, obteve um grau de retenção de valor adicionado de 22,03\%; em 2015, ocorreu uma queda para 5,75\%, e no ano de 2018, teve um relevante aumento para $21,13 \%$. A empresa Iguá, no ano de 2013, obteve um grau de retenção de valor adicionado de 9,16\%; em 2015, ocorreu uma grande queda para $-27,01 \%$, e no ano de 2018 , um aumento de 4,89\%.

Como mostra a Tabela 2, a Sabesp possui um melhor percentual de retenção do valor adicionado, se comparada à Iguá.

\section{f) Grau de Capacidade de Produzir Riqueza (GCPR)}

De acordo com Dalmácio (2004, p. 94), "este índice indica a real capacidade da entidade de produzir riqueza".

$\mathrm{GCPR}=(\mathrm{VALPE} / \mathrm{VAT}) \times 100$

VALPE $=$ Valor Adicionado Líquido Produzido pela Entidade

VAT $=$ Valor Adicionado Total a distribuir

A empresa Sabesp, no ano de 2013, alcançou um grau de capacidade de produção de riqueza de 94,14\%; em 2015, teve uma pequena queda para 84,49\%; no ano de 2016, foi para $94,02 \%$ e, em 2018, subiu para 95,22\%. A empresa Iguá, no ano 2013, atingiu o percentual de $89,37 \%$ na capacidade de produzir riqueza; em 2016, praticamente manteve o mesmo índice, $89,32 \%$ e, no ano de 2018 , teve um pequeno aumento para $93,39 \%$.

Se comparadas as duas empresas, não se observa uma variação muito grande, apesar de a empresa Sabesp possuir índices melhores.

\section{g) Grau de Riqueza Recebida em Transferência (GRRT)}

Na opinião de Dalmácio (2004, p. 95), "este índice indica qual o percentual de riqueza recebida em transferência pela entidade".

$$
\begin{aligned}
& \text { GRRT }=(\text { VART } / \text { VAT }) \times 100 \\
& \text { VART }=\text { Valor Adicionado Recebido em Transferência } \\
& \text { VAT }=\text { Valor Adicionado Total a distribuir }
\end{aligned}
$$

A empresa Sabesp, no ano de 2013, chegou a um grau de riqueza recebida em transferência de 5,86\%; em 2016, houve uma variação para 5,98\% e, no ano de 2018, esse índice diminuiu para 4,78\%. A empresa Iguá, em 2013, atingiu um grau de riqueza recebida em transferência de 10,63\%; no ano de 2015, aumentou para $13,07 \%$ e, no ano de 2018 , o percentual caiu para $6,61 \%$. 
A análise do grau de riqueza recebida mostra, portanto, que a empresa Iguá, quando comparada à SABESP, possui um índice bastante significativo.

\section{h) Grau de Contribuição na Formação de Riqueza de Outras Entidades (GCFROE)}

Esse índice, conforme declara Dalmácio (2004, p. 95), "indica qual o percentual de contribuição de uma entidade na formação de riqueza gerada pela entidade que está sendo transferida para outra entidade".

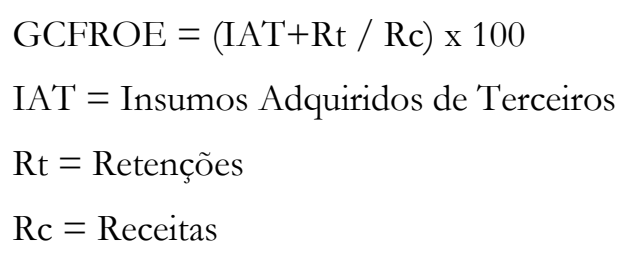

A empresa Sabesp, no ano de 2013, obteve um grau de contribuição na formação de riqueza de outras entidades de $-47,54 \%$; em 2017, chegou a $-8,50 \%$ e, no ano de 2018, $-42,67 \%$. A empresa Iguá, no ano de 2013, atingiu um grau de contribuição na formação de riqueza de outras entidades de - $65,73 \%$; em 2017, diminuiu para $-7,54 \%$ e, no ano de 2018, esse número subiu para $-60,93 \%$.

Ao comparar as duas empresas, observa-se que elas possuem índices parecidos, porém, na Sabesp eles são melhores.

\section{i) Grau de Contribuição dos Ativos na Geração de Riqueza (GCAGR)}

Dalmácio (2004, p. 95) assevera que "este índice indica qual o percentual de contribuição dos ativos na geração de riqueza de uma entidade". O grau de contribuição dos ativos demonstra uma interrelação da DVA com outros demonstrativos contábeis:

$$
\begin{aligned}
& \text { GCAGR }=(\text { VAT } / \text { AT }) \times 100 \\
& \text { VAT }=\text { Valor Adicionado Total a distribuir } \\
& \text { AT }=\text { Ativo Total }
\end{aligned}
$$

A empresa Sabesp, no ano de 2013, obteve um grau de contribuição dos ativos na geração de riqueza de 23,54\%; em 2014, esse número diminuiu para $18,88 \%$ e, no ano de 2018 , chegou a $23,49 \%$. A Iguá, no ano de 2013, alcançou um percentual de contribuição dos ativos na geração de riqueza de 16,09\%; em 2016, diminuiu para 13,14\% e, no ano de 2018, chegou a 15,24\%.

$\mathrm{Na}$ análise do GCAGR, a empresa Sabesp possui índices melhores, se comparados com os da Iguá.

\section{j) Grau de Contribuição do Patrimônio Líquido na Geração de Riqueza (GCPLGR)}

Segundo Dalmácio (2004, p. 96), "este índice indica qual o potencial do capital próprio para geração de riqueza de uma entidade".

$$
\begin{aligned}
& \text { GCPLGR }=(\text { VAT } / \text { PL }) \times 100 \\
& \text { VAT = Valor Adicionado Total a distribuir } \\
& \text { PL }=\text { Patrimônio Líquido }
\end{aligned}
$$


A empresa Sabesp, no ano 2013, obteve um grau de contribuição do patrimônio líquido na geração de riqueza de 23,54\%; no ano de 2014, esse percentual caiu para 18,88\% e, em 2018, chegou a 52,33\%. A empresa Iguá, no ano de 2013, atingiu um grau de contribuição do patrimônio líquido na geração de riqueza de $81,31 \%$; em 2016, subiu para $163,07 \%$ e, no ano de 2018, diminuiu para 51,64\%.

Nesse índice, nota-se que, em relação à Sabesp, a empresa Iguá possui os melhores índices na maioria dos anos analisados.

\subsection{Discussão dos resultados}

A análise dos dados mostra que, quando comparadas, tanto a Sabesp, empresa de capital misto, quanto a Iguá, de capital privado, possuem quase os mesmos valores com relação à distribuição de riqueza entre empregados e governo, ou seja, as distribuições realizadas para a sociedade não apresentam tantas diferenças. Já com relação aos índices de participação de terceiros, a empresa Iguá possui índices maiores que os da Sabesp; no índice de participação dos acionistas, a Sabesp é a que possui índices melhores. É possível afirmar, portanto, que, com relação aos agentes privados, a Sabesp distribui mais para terceiros, enquanto a Iguá faz uma maior distribuição para os acionistas.

Segundo a empresa Iguá, nos anos de 2015 e 2016, as despesas financeiras aumentaram significativamente, ocasionadas, principalmente, pelo aumento dos juros cobrados nos contratos de empréstimos e também das taxas bases (SELIC, IPC e TJLP) adotadas nos contratos de dívida, o que pode explicar os índices tão elevados nesse período.

A empresa Sabesp informou que, no ano de 2014, com a grave seca na região sudeste do Brasil, teve que realizar mais ações estratégicas, maiores investimentos e um contingenciamento orçamentário, para garantir a continuidade do programa de bonificação e a execução das obras planejadas. Todas essas medidas foram levadas para o ano de 2015, o que justifica o aumento de valor adicionado distribuído a terceiros e a diminuição do valor adicionado para os acionistas. Não obstante esse contingenciamento, a referida empresa manteve índices melhores que os da Iguá.

Com base na análise, cabe ressaltar ainda que a Sabesp possui, em relação à Iguá, melhor índice de lucros retidos ou que será agregado ao capital próprio. No que se refere à capacidade de essas empresas produzirem riquezas ou contribuírem para a formação de outras entidades, não foram verificadas grandes variações, apesar de a Sabesp apresentar índices melhores. Com relação ao índice que mostra o percentual de riqueza recebida em transferência, a empresa Iguá sobressai quando comparada com a Sabesp. Já naquele que mostra o percentual de contribuição dos ativos geração da riqueza, a Sabesp possui índices melhores, quando comparados com os da Iguá.

\section{Considerações finais}

Com a evolução da sociedade, cresce a necessidade de se criar meios para conhecer e avaliar as informações das empresas no tocante à sua contribuição com o meio do qual faz parte. Para a consecução dessa finalidade, a contabilidade dispõe da Demonstração do Valor Adicionado, uma ferramenta que ajuda 
a transparecer essas informações de maneira eficiente. A DVA auxilia na relação entre empresas e meio ambiente, visto que fornece informações aos usuários internos e externos.

Conforme o exposto, é possível dizer que o objetivo geral do trabalho, analisar a distribuição da riqueza das empresas Sabesp e Iguá, ambas do setor de água e saneamento, foi alcançado. Sendo uma de capital misto e a outra de capital privado, foram identificadas as variações e distribuições do valor adicionado aos agentes econômicos. Os objetivos específicos também foram atingidos e contribuíram para a fundamentação da análise quanto às variações na Distribuição do Valor Adicionado. Desse modo, a questão de pesquisa foi respondida.

Neste estudo, observou-se que a DVA é relevante para todos os usuários, pois mostra como a empresa contribui para a sociedade. Desse modo, sendo tais empresas de utilidade pública e com capitais de naturezas distintas, saber como é feita a distribuição da riqueza torna-se ainda mais importante.

Para trabalhos futuros, sugere-se ampliar a análise da Demonstração do Valor Adicionado para outras empresas do setor de utilidade pública, com vistas a uma melhor compreensão da relevância dessas entidades para o ambiente. Outra sugestão é fazer um estudo mais aprofundado das empresas por meio do Balanço Social, pois é por meio desse demonstrativo que se obtém um maior número de informações a respeito das empresas.

\section{Referências}

COMITÊ DE PRONUNCIAMENTOS CONTÁBEIS [CPC]. CPC 09 - Demonstração do Valor Adicionado. Disponível em: http://www.cpc.org.br/CPC/DocumentosEmitidos/Pronunciamentos/Pronunciamento?Id=40.

COMITÊ DE PRONUNCIAMENTOS CONTÁBEIS [CPC]. CPC 26 (R1) - Apresentação das Demonstrações Contábeis. Disponível em: http://www.cpc.org.br/CPC/DocumentosEmitidos/Pronunciamentos/Pronunciamento?Id=57.

CRESWELL, John W. Projeto de Pesquisa: Métodos Qualitativo, Quantitativo e Misto. São Paulo: Editora Artmed, 2010.

DALMÁCIO, Flávia Zóboli. Indicadores para análise da Demonstração do Valor Adicionado. Revista Brasileira de Contabilidade [S.I.], n.149, p. 88-97, setembro/outubro. 2004. Disponível em: http://rbc.cfc.org.br/index.php/rbc/article/view/384.

GELBCKE, Ernesto Rubens. et al. Manual de contabilidade societária. São Paulo. Atlas S.A, 2018.

GERHARDT, Tatiana Engel; SILVEIRA, Denise Tolfo. Métodos de Pesquisa. Porto Alegre: Editora da UFRGS, 2009.

GIL, Antonio Carlos. Como Elaborar Projetos de Pesquisa. São Paulo: Editora Atlas S.A, 2010.

HABERKAMP, Angela Maria; MALLMANN, Carine Elisa. A importância da DVA como instrumento de mensuração do Valor Adicionado e da riqueza gerada. Revista Brasileira de Contabilidade, [S.l.], n. 204, p. 24-37, jan. 2014. ISSN 2526-8414. Disponível em: http://rbc.cfc.org.br/index.php/rbc/article/view/1104. 
IGUÁ. Disponível em: https://igua.com.br/quem-somos. Acesso em: 10 de jun. 2021.

KROETZ, César Eduardo Stevens. Balanço Social: teoria e prática. São Paulo: Editora Atlas, 2000.

MARION, José Carlos. Análise das demonstrações contábeis: contabilidade empresarial. 7ed. São Paulo: Editora Atlas, 2012.

PEROTTTONI, Marco Antonio Balanço Social: Responsabilidade, Padronização e Obrigatoriedade. Revista Brasileira de Contabilidade [S.I.], n. 134, p. 50-59, ago. 2011. Disponível em: http://rbc.cfc.org.br/index.php/rbc/article/view/412.

PINTO, Anacleto Laurino; RIBEIRO, Maisa de Souza. O Balanço Social como instrumento de evidenciação de responsabilidade social: um estudo no estado de Santa Catarina. Revista Brasileira de Contabilidade. Brasília, v.34, n. 154, p. 37-49, julho/agosto 2005. Disponível em: http://rbc.cfc.org.br/index.php/rbc/article/view/550.

SABESP. Disponível em: http://site.sabesp.com.br/site/interna/Default.aspx?secaoId=505. Acesso em: 10 de jun. 2021.

SOUZA, Edmilson Patrocínio de. Demonstração do valor adicionado - Evidenciando a distribuição da riqueza gerada pela empresa. Revista Brasileira de Contabilidade, [S.I.], n. 142, p. 20-27, ago. 2003. Disponível em: http://rbc.cfc.org.br/index.php/rbc/article/view/484. 